\title{
Smartphone Medical App Use and Associated Factors Among Physicians at Referral Hospitals in Amhara Region, North Ethiopia, in 2019: Cross-sectional Study
}

Gizaw Hailiye Teferi ${ }^{1}$, BSc, MPH; Binyam Cheklu Tilahun ${ }^{2}$, BSc, MPH, MSc, PhD; Habtamu Alganeh Guadie ${ }^{3}$, BSc, MPH; Ashenafi Tazebew Amare ${ }^{4}$, MD

\footnotetext{
${ }^{1}$ Department of Health Informatics, College of Medicine and Health Science, Debre-Markos University, Debre Markos, Ethiopia

${ }^{2}$ Department of Health Informatics, College of Medicine and Health Sciences, University of Gondar, Gondar, Ethiopia

${ }^{3}$ School of Public Health, College of Medicine and Health Science, Bahir Dar University, Bahir Dar, Ethiopia

${ }^{4}$ Department of Pediatrics, College of Medicine and Health Science, University of Gondar, Gondar, Ethiopia
}

\section{Corresponding Author:}

Gizaw Hailiye Teferi, BSc, MPH

Department of Health Informatics

College of Medicine and Health Science

Debre-Markos University

PO Box: 269

Debre Markos

Ethiopia

Phone: 251921493560

Email: ghailiye463@gmail.com

\section{Abstract}

Background: Information in health care is rapidly expanding and is updated very regularly, especially with the increasing use of technology in the sector. Due to this, health care providers require timely access to the latest scientific evidence anywhere. Smartphone medical apps are tools to access the latest reputable scientific evidence in the discipline. In addition, smartphone medical apps could lead to improved decision making, reduced numbers of medical errors, and improved communication between hospital medical staff.

Objective: The aim of this study was to assess smartphone medical app use and associated factors among physicians working at referral hospitals of the Amhara region, Ethiopia.

Methods: An institution-based cross-sectional study design was conducted among physicians working at 5 referral hospitals in the Amhara region, Ethiopia, from February 5 to May 27, 2019. A simple random sampling method was used to select 423 physicians. A self-administered questionnaire was used to collect the data and analyzed using SPSS, version 21 (IBM Corp). Binary and multivariable logistic regression analysis was performed to assess factors associated with smartphone medical app use among physicians. A value of $P<.05$, corresponding to a $95 \% \mathrm{CI}$, was considered statistically significant. The validity of the questionnaire was determined based on the view of experts and the reliability of it obtained by calculating the value of Cronbach alpha $(\alpha=.78)$

Results: In this study, most of the 417 respondents $(375,89.9 \%)$ had medical apps installed on their smartphones. Of those 375 respondents, $264(70.4 \%)$ had used medical apps during clinical practice. The medical apps most commonly used by the respondents were UpToDate, Medscape, MedCalc, and Doximity. According to multivariable logistic regression analysis, attitude (adjusted odds ratio [AOR] 1.64, 95\% CI 1.05-2.55), internet access (AOR 2.82, 95\% CI 1.75-4.54), computer training (AOR 1.71, 95\% CI 1.09-2.67), perceived usefulness of the app (AOR 1.64, 95\% CI 1.05-2.54), information technology support staff (AOR 2.363, 95\% CI 1.5-3.08), and technical skill (AOR 2.52, 95\% CI 1.50-4.25) were significantly associated with smartphone medical app use.

Conclusions: Most respondents have a smartphone medical app and have used it in clinical practice. Attitude, internet access, computer training, perceived usefulness of the app, information technology support staff, and technical skill are the most notable factors that are associated with smartphone medical app use by physicians. 
(JMIR Mhealth Uhealth 2021;9(3):e19310) doi: 10.2196/19310

\section{KEYWORDS}

application; medical; physician; smartphone; mobile phone

\section{Introduction}

The main sources of information for health care professionals at the point of care were once textbooks [1]. However, health care professionals increasingly use smartphone medical apps for patient care, clinical reference, and education [2]. The smartphone is a tool that has recently grown in use and has been accepted by health professionals and medical students. It is a new technology that has an operating system, the capability of installing various apps, and the ability to do complex calculations and establish related communications at the point of care [1,3]. Smartphone apps are tools that can be downloaded onto smartphones or computer tablets and enhance patient care, increase efficiency, or provide individualized learning for clinicians [4]. In 2011, Apple created the Apps for Healthcare Professionals section within the medical category of the iTunes App Store, a unique feature among mobile app marketplaces [5]. Smartphones have a wide range of uses from the internet to email; they offer on-the-go access to information that was never before possible [6]. The most commonly used smartphone medical apps are UpToDate and Medscape, as shown in Table 1 .

Table 1. Summary of the most commonly used smartphone medical apps.

\begin{tabular}{llll}
\hline Rank & App & App category & Operating system \\
\hline 1 & UpToDate & Medical reference & iOS, Android, Windows \\
2 & Medscape & Medical reference & iOS, Android, Windows \\
3 & Epocrates & Drug and medical reference & iOS, Android, Windows \\
4 & PEPID & Decision support/reference & iOS, Android, Windows \\
5 & Figure 1 & Medical image & iOS, Android, Windows \\
6 & MedCalc & Drug reference & iOS, Android, Windows \\
7 & Prognosis & Decision support/reference & iOS, Android, Windows \\
8 & Skyscape & Drug and medical reference & iOS, Android, Windows \\
9 & Diseases Dictionary Medical & Medical disorders \& diseases with detailed definitions, symptoms, causes, & iOS, Android, Windows \\
& & and treatment information & iOS, Android, Windows \\
\hline
\end{tabular}

A study conducted in the United Kingdom showed that smartphone medical apps like British National Formulary, eLogbook, and medical calculator (MedCalc) have been commonly used by physicians [7]. This technology can lead to improved decision making, reduced numbers of medical errors, and improved communication between hospital medical staff [8-10].

Another study from the United Kingdom stated that due to the ease of use of smartphone medical apps, $18.5 \%$ of doctors made suggestions to their colleagues to use apps as a quick reference during clinical practice [7]. However, lack of support and updating of apps by their developers, lack of adequate skill to use apps, lack of creating motivation in using apps, and problems related to security and confidentiality of patient information have undermined the use of smartphone medical apps at the point of care [10-12]. A study conducted in Korea showed low use of smartphone medical apps by physicians [13].

Evidence shows that medical app use is high in high-income countries; compared with the Korean study, a study conducted in the United Kingdom found higher medical app use (72.4\%) among doctors [14].

Another study in the United States reported that $56 \%$ of physicians use apps in their clinical practice. There was a decreasing trend in app use with increased training level, and the most useful app types included textbook and reference materials (average response: $55 \%$ ), classification and treatment algorithms (46\%), and general medical knowledge (43\%); there was a greater desire for apps among residents than among fellows and attending physicians [15]. This might be due to residents being less experienced physicians than the senior specialists and subspecialists; as a result, they need some assistance from colleagues and seniors, so medical apps are immediate reference tools that can be accessed anywhere during clinical practice. This explains why the level of use among residents is higher than among their senior attending physicians.

A study conducted in Saudi Arabia showed the use patterns of smartphone medical apps among residents at clinical practice for counselling and clinical communication (50\%), among interns for drug reference (56\%), and among externs for resources and e-books (65\%) [16].On the other hand, a study done in Iran reported that the most popular medical apps were Medscape and UpToDate, and $61.3 \%$ of the physicians were using their apps more than once a day, mostly for drug information [17].

According to a cross-sectional study done in Ghana, over $43.1 \%$ of physicians frequently used medical apps on their smartphones 
for clinical decision making, which shows relatively low use of medical apps compared with that in high-income countries [18].

Due to different factors, physicians remain reluctant to adopt these technologies in clinical practice [2]; the most common factors that affect the use of smartphone medical apps are behavioral factors (information technology (IT)-related experience, attitude, computer-related skill) [19], factors related to medical app characteristics (perceived usefulness, perceived ease of use, privacy and security concerns), organizational factors (infrastructure, IT support, and computer-related training) [20]. Shreds of evidence revealed that underutilization of apps in clinical practice by health care professionals is due to a lack of technical skill [21]. According to the findings of a cross-sectional study conducted in the United Kingdom, appearing to be looking at a phone during clinical practice could be misinterpreted as checking emails or using social networks by colleagues and patients [7,22-25].

Security and privacy are the key factors of the functionality of any mHealth system [26]; unfortunately, most of the time these important areas are neglected by development teams of mHealth systems, and the majority of currently available mHealth apps impart little or no security. This will affect the use of these apps significantly [27-29]. Perceived ease of use is another factor that determines the use of smartphone medical apps; those with a user-friendly interface are more likely to be used [23]. The aim of this study was to assess the level of smartphone medical app use and associated factors among physicians in referral hospitals of the Amhara region, Ethiopia.

\section{Methods}

\section{Study Design and Setting}

This was a cross-sectional, questionnaire-based study done to assess smartphone medical app use and associated factors among physicians in referral hospitals (Gondar University, Felege Hiwot, Debre Markos, Dessie, and Debre Birhan referral hospitals) in Amhara region, Ethiopia, which consists of 10 administrative zones, 1 special zone, 181 woredas, and 78 urban centers. The capital city of the state of Amhara is Bahir-Dar [30]. It is located in the northwestern and north-central parts of Ethiopia. The state shares common borders with the state of Tigray in the north, Afar in the east, Oromia in the south, Benishangul/Gumuz in the southwest, and the Republic of Sudan in the west [31].

The sample size was computed as 423 , which was $80 \%$ of the total population during the data collection period, using a single population proportion formula taking $50 \%$ at a $95 \%$ confidence level and assuming a 5\% margin of error and $10 \%$ nonresponse rate. There are 5 referral hospitals in the region; all 5 referral hospitals were included, and then proportional allocation was made for each hospital. Finally, a simple random sampling method was used. 213 permanent doctors (general practitioners and specialists), 95 residents, and 115 interns were recruited using a lottery method (each member of the population was assigned a unique number, each number was written on a separate piece of paper or card of the same size, the cards were mixed well in a basket, and the sample was drawn) and formed the sample.

The survey consisted of 36 questions encompassing the following domains: (1) sociodemographic characteristics, (2) attitude, (3) factors related to medical app characteristics (perceived usefulness and perceived ease of use of apps), (4) physician technical skill, and (5) organizational factors [20].

Attitude was assessed using a Likert scale (1=strongly disagree, $2=$ disagree, $3=$ neutral, $4=$ agree, $5=$ strongly agree) for the following questions: Do you believe smartphone medical apps give you greater control over your work schedule? Do you believe smartphone medical apps will improve your work performance? Do you think smartphone medical apps allow you to conduct your job more quickly?

Organizational factors were assessed with yes/no questions as follows: Do you have internet access in your office at clinical practice? Have you ever taken any training on use of smartphone medical apps? Does your organization have IT support staff?

Perceived usefulness and ease of use of medical apps were assessed using a Likert scale (1=strongly disagree, $2=$ disagree, $3=$ neutral, $4=$ agree, $5=$ strongly agree) for questions such as the following: Do you think learning to use smartphone medical apps will not require much time? Do you think smartphone medical apps are easy to use? Do you think smart phone medical apps are easy to use during your consultations with patients?

Smartphone medical app use was assessed using 9 categories of medical apps: (1) drug reference, (2) clinical score systems, (3) disease diagnosis, (4) procedure documentation, (5) literature search, (6) clinical communication, (7) health information system clients, (8) medical training, and (9) web browsing. Physicians who used 5 or more of the app categories, which was the median, were categorized as having used smartphone medical apps and those who used fewer than 5 were not.

A self-administered questionnaire was adopted from previous studies $[14,32]$. To ensure the validity of the questionnaire, an expert panel (10 doctors having at least 5 years' experience in general practice or primary care research) was invited to review the tool and revise it, and reliability was calculated to be $\alpha=78$.

Before the actual data collection, pilot testing of the questionnaire was conducted among 20 physicians at Debre Tabor hospital to check internal consistency within the questioners. Then necessary correction was done based on the pretest finding.

Two days' training was given for 5 data collectors on the objective of the study and data collection procedures. Data was collected from January 15 to March 30, 2019, using self-administered questionnaires; one data collector was assigned for each hospital, and the supervisor facilitated the data collection process. The principal investigator and supervisors did daily supportive supervision on data collectors. Data backup activities, such as storing data at different places and putting data in different formats (hard and soft copies), were performed to prevent data loss. 


\section{Study Variables and Operational Definitions \\ Dependent Variable}

The dependent variable was the physician's smartphone medical app use.

\section{Independent Variables}

The independent variables were sociodemographic factors (age, sex, profession, educational status, experience), medical app-related factors (perceived usefulness, perceived ease of use, privacy and security concerns), organizational factors (internet access, IT support, computer-related training), and behavioral factors (knowledge, attitude, technical skill, IT-related experience).

\section{Operational Definitions}

In this study, "physician" includes general practitioners, residents, dentists, specialists, and subspecialists.

Smartphone is a class of mobile phone with multipurpose mobile computing capability and features like high-definition camera, third-party app installation, and global positioning system [33]

Medical apps are computer programs or software apps that are designed to run on a mobile device such as a smartphone or tablet and are meant to be used for clinical purposes.

Smartphone medical apps are medical apps designed to run specifically on smartphones [34].

Study participants who scored at or above the median of 5 out of the 9 categories of Food and Drug Administration-approved medical apps were categorized as having used smartphone medical apps [18].

For the attitude questions, study participants who scored the median or higher on the 5-point Likert scale were categorized as having a good attitude, and those who scored below the median were categorized as having a poor attitude [35].

For the perceived usefulness questions, study participants who scored the median or higher on the 5-point Likert scale were categorized as thinking smartphone medical apps were useful for their job, and those who scored below the median were categorized as thinking smartphone medical apps were not useful for their job [36].

For the perceived ease of use questions, study participants who scored the median or higher on the 5-point Likert scale were categorized as thinking smartphone medical apps were easy to use, and those who scored below the median were categorized as thinking smartphone medical apps were not easy to use.

\section{Data Processing and Analysis}

Data were entered into Epi Info, version 7 (Centers for Disease Control and Prevention), and exported to SPSS, version 21 (IBM Corp), for further analysis. Descriptive statistics were computed to summarize variables, and the binary logistic regression model was used to measure the association between dependent and independent variables. Both crude odds ratios for binary logistic regression analysis and adjusted odds ratios (AOR) for multivariable logistic regression analysis were estimated with $95 \%$ CIs to show the strength of associations. Finally, a $P$ value of less than .05 in the multivariable logistic regression analysis was used to identify variables significantly associated with the use of smartphone medical apps.

\section{Ethical Considerations}

In conducting the study, ethical clearance was obtained from the University of Gondar ethical review board. Additional permissions to access participants were also obtained from each hospital administrator. In addition, written informed consent was gained from all participants (Multimedia Appendix 1), participation in the study was voluntary, and no incentive was provided for the participants.

\section{Results}

\section{Sociodemographic Characteristics}

A total of 417 physicians were included in this study with a response rate of $98.6 \%$ (417/423). Two-thirds $(275,65.9 \%)$ of the respondents were male. The mean age was 33 years (SD 8) with the majority in the age group of 25-34 years. More than three-fourths $(375,89.9 \%)$ of the physicians had the medical app installed on their smartphones (Table 2). 
Table 2. Sociodemographic characteristics of respondents working at referral hospitals of Amhara region, North Ethiopia, 2019 (N=417).

\begin{tabular}{|c|c|}
\hline Variable & $\mathrm{n}(\%)$ \\
\hline \multicolumn{2}{|l|}{ Gender } \\
\hline Male & $275(65.9)$ \\
\hline Female & $142(34.1)$ \\
\hline \multicolumn{2}{|l|}{ Age (years) } \\
\hline$\leq 30$ & $217(52.0)$ \\
\hline$>30$ & $200(48.0)$ \\
\hline \multicolumn{2}{|l|}{ Educational status } \\
\hline General practitioner & $219(52.5)$ \\
\hline Resident & $127(30.5)$ \\
\hline Specialist & $71(17.0)$ \\
\hline \multicolumn{2}{|l|}{ Department } \\
\hline Internal medicine & $80(19.2)$ \\
\hline Pediatrics & $54(12.9)$ \\
\hline Radiology & $28(6.7)$ \\
\hline Surgery & $67(16.1)$ \\
\hline Ophthalmology & $25(6.0)$ \\
\hline Gynecologist & $65(15.6)$ \\
\hline Dermatology & $18(4.3)$ \\
\hline $\mathrm{ENT}^{\mathrm{a}}$ & $36(8.6)$ \\
\hline Other & $44(10.6)$ \\
\hline \multicolumn{2}{|l|}{ Work experience (years) } \\
\hline $1-3$ & $231(55.4)$ \\
\hline $3-6$ & $91(21.8)$ \\
\hline$>6$ & $95(22.8)$ \\
\hline \multicolumn{2}{|l|}{ Medical app ownership } \\
\hline Yes & $375(89.9)$ \\
\hline No & $42(10.1)$ \\
\hline
\end{tabular}

${ }^{\mathrm{a}}$ ENT: ear, nose, and throat.

\section{Smartphone Medical App Use of Physicians at Referral Hospitals}

According to this study, $63.3 \%$ (264) of the respondents reported that they use apps in their clinical practice (95\% CI $58.3 \%-67.9 \%$ ), and the most commonly used smartphone medical app category was diagnosis/management (62\%) (Table $3)$.

According to this study, the most commonly used smartphone app was UpToDate (300/417, 71.9\%) (Table 4).

Most study respondents $(354,85 \%)$ used their apps daily, while $10.5 \%$ used them 3 times a week (Table 5). 
Table 3. Smartphone medical app use at referral hospitals among physicians, 2019 (N=417).

\begin{tabular}{|c|c|c|c|c|}
\hline \multirow[t]{2}{*}{ Medical app types } & \multicolumn{4}{|l|}{ Education level } \\
\hline & General practitioner, $\mathrm{n}$ & Resident, $\mathrm{n}$ & Specialist, $\mathrm{n}$ & Total, n (\%) \\
\hline Disease diagnosis & 134 & 84 & 43 & $261(62.6 \%)$ \\
\hline Literature search & 120 & 67 & 31 & $218(52.3 \%)$ \\
\hline Browsing & 113 & 54 & 29 & $196(47.0 \%)$ \\
\hline HIS $^{\mathrm{a}}$ clients & 106 & 54 & 35 & $195(46.8 \%)$ \\
\hline Clinical score system & 104 & 71 & 34 & $209(50.1 \%)$ \\
\hline Medical training & 104 & 59 & 31 & $194(46.5)$ \\
\hline Drug reference & 97 & 48 & 28 & $173(41.5)$ \\
\hline Clinical communication & 87 & 58 & 23 & $168(40.3 \%)$ \\
\hline Procedure documentation & 73 & 51 & 28 & $152(36.5 \%)$ \\
\hline
\end{tabular}

${ }^{\mathrm{a}} \mathrm{HIS}$ : health information system.

Table 4. Medical apps used by physicians working at referral hospitals in Amhara regional state, Ethiopia, 2019.

\begin{tabular}{|c|c|}
\hline App used & $\mathrm{n}(\%)$ \\
\hline \multicolumn{2}{|c|}{ UpToDate } \\
\hline Yes & $305(73.1)$ \\
\hline No & $112(26.9)$ \\
\hline \multicolumn{2}{|l|}{ Medscape } \\
\hline Yes & $276(66.2)$ \\
\hline No & $141(33.8)$ \\
\hline \multicolumn{2}{|l|}{ MedCalc } \\
\hline Yes & $226(54.2)$ \\
\hline No & $192(46.0)$ \\
\hline \multicolumn{2}{|l|}{ Doximity } \\
\hline Yes & 104 (24.9) \\
\hline No & $313(75.1)$ \\
\hline \multicolumn{2}{|l|}{ PEPID } \\
\hline Yes & $50(12.0)$ \\
\hline No & $367(88.0)$ \\
\hline \multicolumn{2}{|l|}{ Case } \\
\hline Yes & $97(23.3)$ \\
\hline No & $320(76.7)$ \\
\hline \multicolumn{2}{|l|}{ Figure 1} \\
\hline Yes & 99 (23.7) \\
\hline No & $318(76.3)$ \\
\hline \multicolumn{2}{|c|}{ Read by QxMD } \\
\hline Yes & 90 (21.6) \\
\hline No & $327(78.4)$ \\
\hline
\end{tabular}


Table 5. Frequency of smartphone medical app use among physicians working at referral hospitals of Amhara regional state, 2019 (N=375).

\begin{tabular}{|c|c|c|c|c|}
\hline \multirow[t]{2}{*}{ Medical app } & \multicolumn{4}{|c|}{ Frequency of use, n (\%) } \\
\hline & Daily & Three times a week & Once a week & I don't know \\
\hline UpToDate & $333(88.8)$ & $28(7.5)$ & $12(3.2)$ & $2(0.5)$ \\
\hline Medscape & $335(89.3)$ & $25(6.7)$ & $13(3.5)$ & $2(0.5)$ \\
\hline MedCalc & $346(92.3)$ & $18(4.8)$ & $9(2.4)$ & $2(0.5)$ \\
\hline Doximity & $340(90.7)$ & $23(6.1)$ & $12(3.2)$ & 0 \\
\hline Figure 1 & $339(90.4)$ & $24(6.4)$ & $12(3.2)$ & 0 \\
\hline Read by QxMD & $335(89.3)$ & $27(7.2)$ & $13(3.5)$ & 0 \\
\hline Case & $346(92.3)$ & $21(5.6)$ & $8(2.1)$ & 0 \\
\hline PEPID & $322(85.9)$ & $18(4.8)$ & $35(9.3)$ & 0 \\
\hline
\end{tabular}

\section{Factors Associated With Smartphone Medical App Use Among Physicians}

A total of 6 variables were selected as potential predictors of smartphone app use after bivariable logistic regression and entered multivariable logistic regression. Included variables were attitude, internet access, computer training, past IT experience, perceived ease of use of the app, perceived usefulness of the app, the technical skill of the physicians, and availability of IT support staff, which were positively related to smartphone medical app use by physicians at referral hospitals in Amhara region.

In this study, physicians with a favorable attitude toward smartphone medical apps were 1.64 times more likely to use them than physicians with an unfavorable attitude were (AOR $1.64,95 \%$ CI 1.05-2.55). Similarly, physicians who have IT support staff at hospitals were 2.36 times more likely to be smartphone medical app users compared to their counterparts (AOR 2.36, 95\% CI 1.5-3.08) (Table 6). 
Table 6. Bivariable and multivariable regression analysis of factors with smartphone medical app use among physicians in referral hospitals of Amhara regional state, North Ethiopia, 2019 ( $\mathrm{N}=417)$.

\begin{tabular}{|c|c|c|c|c|c|}
\hline \multirow[t]{2}{*}{ Variable } & \multicolumn{2}{|c|}{ App use, n (\%) } & \multirow[t]{2}{*}{ Crude $\mathrm{OR}^{\mathrm{a}}(95 \% \mathrm{CI})$} & \multirow[t]{2}{*}{$\mathrm{AOR}^{\mathrm{b}}(95 \% \mathrm{CI})$} & \multirow[t]{2}{*}{$P$ value } \\
\hline & Yes & No & & & \\
\hline \multicolumn{6}{|c|}{ Education level } \\
\hline $\mathrm{GP}^{\mathrm{c}}$ & $142(34.1)$ & $77(18.5)$ & $1.51(0.87-2.60)$ & $1.68(0.91-3.10)$ & $-^{\mathrm{d}}$ \\
\hline Resident & 83 (19.9) & $44(10.6)$ & $1.54(0.85-2.80)$ & $1.70(0.88-3.30)$ & - \\
\hline Specialist & $39(9.4)$ & $32(7.7)$ & 1 & 1 & - \\
\hline \multicolumn{6}{|l|}{ Internet access } \\
\hline Yes & $210(50.4)$ & $88(21.1)$ & $2.87(1.85-4.45)$ & $2.82(1.75-4.50)$ & $<.001$ \\
\hline No & $54(12.9)$ & $65(15.6)$ & 1 & 1 & - \\
\hline \multicolumn{6}{|c|}{ Computer training } \\
\hline Yes & $179(42.9)$ & $72(17.3)$ & $2.36(1.57-3.56)$ & $1.71(1.09-2.67)$ & $<.001$ \\
\hline No & $85(20.4)$ & $81(19.4)$ & 1 & 1 & - \\
\hline \multicolumn{6}{|c|}{ IT support staff } \\
\hline Yes & $156(37.4)$ & $58(13.9)$ & $2.366(1.57-3.56)$ & $2.363(1.50-3.08)$ & .001 \\
\hline No & $108(25.9)$ & $95(22.8)$ & 1 & 1 & - \\
\hline \multicolumn{6}{|l|}{ Technical skill } \\
\hline Yes & $225(54)$ & $103(24.7)$ & $2.8(1.73-4.52)$ & $2.54(1.50-4.30)$ & $<.001$ \\
\hline No & $39(9.4)$ & $50(12.0)$ & 1 & 1 & - \\
\hline \multicolumn{6}{|l|}{ Attitude } \\
\hline Yes & $153(36.7)$ & $69(16.5)$ & $1.67(1.12-2.50)$ & $1.64(1.05-2.55)$ & .01 \\
\hline No & $111(26.6)$ & $84(20.1)$ & 1 & 1 & - \\
\hline \multicolumn{6}{|c|}{ Perceived usefulness } \\
\hline Yes & $158(37.9)$ & $70(16.8)$ & $1.76(1.18-2.64)$ & $1.65(1.06-2.56)$ & .02 \\
\hline No & $106(25.4)$ & $83(19.9)$ & 1 & 1 & - \\
\hline
\end{tabular}

${ }^{\mathrm{a} O R}$ : odds ratio.

${ }^{\mathrm{b}}$ AOR: adjusted odds ratio.

${ }^{\mathrm{c}} \mathrm{GP}$ : general practitioner.

${ }^{\mathrm{d}}$ Not available.

\section{Discussion}

\section{Principal Findings}

This study assessed the use of smartphone medical apps and associated factors among physicians at referral hospitals in the Amhara region. Out of 417 participants, 375 (89.9\%) have a medical app installed on their mobile device, and disease diagnosis/management was the most commonly used medical app category. Factors like attitude, perceived usefulness, internet access, and past computer-related training were found to be associated with smartphone medical app use. In this study, the use rate of smartphone medical apps by physicians was $63.3 \%$ (95\% CI 58.3\%-67.9\%). This result was consistent with that of a study done in Britain (60\%) [6]. On the other hand, it was lower than those of a study done in Canada (77.0\%) [11], a study conducted in Germany at the Leipzig Medical School (68\%) [37], and a study conducted in the United States on the American Society of Plastic Surgeons (72\%) [38]. This might be due to well-organized infrastructure at the clinical practice site, awareness of physicians on the use of smartphone medical apps for patient care, and availability of technological guidelines that promote the use of smartphone medical apps in America, Canada, and Germany. On the other hand, the result is higher than that of a study in Ghana (43.1\%) [18]. A possible explanation may be due to the sample size difference (the sample size of the study in Ghana was 65) and the study period (this study was conducted about 4 years ago).

This study indicated that the medical apps most frequently used by physicians were UpToDate, Medscape, and MedCalc. This result is in line with the study conducted in Canada [11]. Most of the physicians $(271 / 375,72.3 \%)$ preferred smartphone medical apps as an information source for reference during clinical practice. The proportion is lower in the study in Ghana than in this study; this might be due to the accessibility of smartphones in our setup and sample size difference (the sample size of the study in Ghana was 65) [18]. 
This study found that the perceived usefulness of smartphone medical apps was positively associated with medical app use among physicians at referral hospitals in the Amhara region $(P=.04)$. This is in line with a study conducted in Taiwan [39]. Perceived usefulness of apps was a significant determinant of app use according to a study conducted in a Malaysian public hospital [40]. That result is comparable with this current study (OR 1.65, 95\% CI 1.06-2.56]).

This study revealed that physicians who had good technical skills were 2.54 times more likely to use smartphone medical apps at clinical practice than those who had poor technical skills (AOR 2.54, 95\% CI 1.50-4.30]). A study conducted in Czech Republic also indicated that technical skill was a factor for smartphone app use [41]. This might be because people with good technical skills are more receptive to new technology and capable of operating new apps.

According to this study, physicians who were working in an institution with internet access (WiFi) were 2.82 times more likely to use smartphone medical apps than those who had no internet access (AOR 2.82, 95\% CI 1.75-4.54). This might be because the availability of internet access makes the regular update of medical apps easier and makes it possible to exchange information through a medical app, such as for consultation among senior physicians.

Physicians who were in an institution that has IT support staff were 2.36 times more likely to use smartphone medical apps than their counterparts (AOR 2.363, 95\% CI 1.50-3.08).

This study revealed that the odds of physicians with favorable attitudes being users of smartphone medical apps were 1.64 times higher than those of their counterparts (AOR 1.64, 95\% CI 1.05-2.55), which is in line with the result obtained by a study conducted in Iran [35].
This implies that the attitude of physicians is key in the implementation of such apps in clinical practice. From the results above, we found that smartphone medical apps used by physicians did well in providing relevant medical information during clinical practice and received positive reviews from physicians. However, in other aspects (ie, outside of improving clinical decision making, saving time, helping to make differential diagnoses, performing useful medical-related calculations, and providing faster access to evidence-based medical practices or cases), medical apps did not meet the needs of physicians well, as most of the medical apps are not freely accessible, the cost of these apps is not affordable, and more importantly, the payment mechanism is not available in our country, Ethiopia. Therefore, in the future, there will be much room for improvement, and health care institutions in resource-limited countries like Ethiopia should offer an institutional access mechanism to such medical apps that is accessible freely.

\section{Conclusion}

The findings of this study showed that smartphone medical app use was $63.3 \%$. Favorable attitude, internet access, computer training, perceived usefulness of the app, the technical skill of the physicians, and availability of IT support staff were the most notable factors that were associated with smartphone medical app use.

Based on this result, smartphone medical apps have inevitable contributions to successful and effective clinical practice. To effectively use this technology in clinical practice, health care organizations should create awareness of its use and implications in health care service, improve internet connectivity, and provide training on the use of these apps.

\section{Acknowledgments}

We would like to thank the University of Gondar Institute of Public Health for the approval of the ethical clearance and the referral hospitals and directors for giving us permission to collect data. We also forward gratitude to the data collectors, supervisors, and study participants.

This work would not be possible without the financial support of the Doris Duke Charitable Foundation under grant number 2017187. The mission of the Doris Duke Charitable Foundation is to improve the quality of people's lives through grants supporting the performing arts, environmental conservation, medical research, and child well-being and through preservation of the cultural and environmental legacy of Doris Duke's properties.

\section{Authors' Contributions}

GHT conceived of the study and coordinated data collection. GHT, BCT, ATA, and HAG performed statistical analysis and drafted the manuscript. All authors read and approved the final manuscript.

\section{Conflicts of Interest}

None declared.

\section{Multimedia Appendix 1}

Informed consent statement.

[DOCX File, 16 KB-Multimedia Appendix 1]

\section{References}


1. Mosa ASM, Yoo I, Sheets L. A systematic review of healthcare applications for smartphones. BMC Med Inform Decis Mak 2012;12:67 [FREE Full text] [doi: 10.1186/1472-6947-12-67] [Medline: 22781312]

2. Ventola CL. Mobile devices and apps for health care professionals: uses and benefits. P T 2014 May;39(5):356-364 [FREE Full text] [Medline: 24883008]

3. Wu RC, Morra D, Quan S, Lai S, Zanjani S, Abrams H, et al. The use of smartphones for clinical communication on internal medicine wards. J Hosp Med 2010;5(9):553-559. [doi: 10.1002/jhm.775] [Medline: 20690190]

4. Rodrigues M, Visvanathan A, Murchison J, Brady R. Radiology smartphone applications; current provision and cautions. Insights Imaging 2013 Oct;4(5):555-562 [FREE Full text] [doi: 10.1007/s13244-013-0274-4] [Medline: 23912880]

5. Thomairy NA, Mummaneni M, Alsalamah S, Moussa N, Coustasse A. Use of Smartphones in Hospitals. Health Care Manag (Frederick) 2015;34(4):297-307. [doi: 10.1097/HCM.0000000000000080] [Medline: 26506291]

6. Lindquist AM, Johansson PE, Petersson GI, Saveman B, Nilsson GC. The use of the Personal Digital Assistant (PDA) among personnel and students in health care: a review. J Med Internet Res 2008;10(4):e31 [FREE Full text] [doi: 10.2196/jmir.1038] [Medline: 18957381]

7. Patel RK, Sayers AE, Patrick NL, Hughes K, Armitage J, Hunter IA. A UK perspective on smartphone use amongst doctors within the surgical profession. Ann Med Surg (Lond) 2015 Jun;4(2):107-112 [FREE Full text] [doi: 10.1016/j.amsu.2015.03.004] [Medline: 25905017]

8. Prgomet M, Georgiou A, Westbrook JI. The impact of mobile handheld technology on hospital physicians' work practices and patient care: a systematic review. J Am Med Inform Assoc 2009;16(6):792-801 [FREE Full text] [doi: 10.1197/jamia.M3215] [Medline: 19717793]

9. Wu R, Rossos P, Quan S, Reeves S, Lo V, Wong B, et al. An evaluation of the use of smartphones to communicate between clinicians: a mixed-methods study. J Med Internet Res 2011;13(3):e59 [FREE Full text] [doi: 10.2196/jmir.1655] [Medline: 21875849]

10. Armstrong DG, Giovinco N, Mills JL, Rogers LC. FaceTime for Physicians: Using Real Time Mobile Phone-Based Videoconferencing to Augment Diagnosis and Care in Telemedicine. Eplasty 2011 May 03;11:e23 [FREE Full text] [Medline: 21559249]

11. Boruff JT, Storie D. Mobile devices in medicine: a survey of how medical students, residents, and faculty use smartphones and other mobile devices to find information. J Med Libr Assoc 2014 Jan;102(1):22-30 [FREE Full text] [doi: 10.3163/1536-5050.102.1.006] [Medline: 24415916]

12. Jebraeily M, Fazlollahi Z, Rahimi B. The Most Common Smartphone Applications Used By Medical Students and Barriers of Using Them. Acta Inform Med 2017 Dec;25(4):232-235 [FREE Full text] [doi: 10.5455/aim.2017.25.232-235] [Medline: 29284911]

13. Safdari R, Jebraeily M, Rahimi B, Doulani A. Smartphone medical applications use in the clinical training of medical students of UMSU and its influencing factors. Eur J Exp Biol 2014;4(1):633-637.

14. Payne KFB, Wharrad H, Watts K. Smartphone and medical related App use among medical students and junior doctors in the United Kingdom (UK): a regional survey. BMC Med Inform Decis Mak 2012 Oct 30;12:121 [FREE Full text] [doi: 10.1186/1472-6947-12-121] [Medline: 23110712]

15. Franko OI, Tirrell TF. Smartphone app use among medical providers in ACGME training programs. J Med Syst 2012 Oct;36(5):3135-3139. [doi: 10.1007/s10916-011-9798-7] [Medline: 22052129]

16. Alfawareh HM, Jusoh S. Smartphones usage among university students: Najran University case. IJAR 2014 Mar 30;6(2):321-326. [doi: 10.7813/2075-4124.2014/6-2/B.48]

17. Jahanshir A, Karimialavijeh E, Sheikh H, Vahedi M, Momeni M. Smartphones and Medical Applications in the Emergency Department Daily Practice. Emerg (Tehran) 2017 Jan 09;5(1):e14 [FREE Full text] [Medline: 28286821]

18. Senya KY. Use of Smart Phone Applications for Clinical Decision Making Among Junior Medical Practitioners in Selected Health Facilities in The Greater Accra Region, Ghana. Ghana: University of Ghana; 2015 Nov 11. URL: http://ugspace. ug.edu.gh/bitstream/handle/123456789/8208/

KAFUI\%20YAYRA\%20SENYA_USE\%20OF\%20SMART\%20PHONE\%20APPLICATIONS\%20FOR\%20CLINICAL_2015. pdf [accessed 2019-06-07]

19. Jeon E, Park H. Factors affecting acceptance of smartphone application for management of obesity. Healthc Inform Res 2015 Apr;21(2):74-82 [FREE Full text] [doi: 10.4258/hir.2015.21.2.74] [Medline: 25995959]

20. Gagnon M, Ngangue P, Payne-Gagnon J, Desmartis M. m-Health adoption by healthcare professionals: a systematic review. J Am Med Inform Assoc 2016 Jan;23(1):212-220 [FREE Full text] [doi: 10.1093/jamia/ocv052] [Medline: 26078410]

21. Zahra F, Hussain A, Mohd H. Factors affecting mobile health application for chronic diseases. J Telecommun Electron Comput Eng 2018;10:81.

22. Chen J, Park Y, Putzer G. An examination of the components that increase acceptance of smartphones among healthcare professionals. Electron J Heal Informatics 2010;5(2):1-12. [doi: 10.4018/978-1-4666-9828-4.les10]

23. Lee S, Choi MJ, Rho MJ, Kim D, Choi IY. Factors Affecting User Acceptance in Overuse of Smartphones in Mobile Health Services: An Empirical Study Testing a Modified Integrated Model in South Korea. Front Psychiatry 2018;9:658 [FREE Full text] [doi: 10.3389/fpsyt.2018.00658] [Medline: $\underline{\text { 30631283] }}$ 
24. Shenouda JEA, Davies BS, Haq I. The role of the smartphone in the transition from medical student to foundation trainee: a qualitative interview and focus group study. BMC Med Educ 2018 Jul 31;18(1):175 [FREE Full text] [doi: 10.1186/s12909-018-1279-y] [Medline: $\underline{\text { 30064424] }}$

25. Nematollahi M, Faghiri K, Barati O, Bastani P. Smart Phone Acceptance among Physicians: Application of Structural Equation Modelling in the Largest Iranian University. J Biomed Phys Eng 2017 Mar;7(1):87-94 [FREE Full text] [Medline: 28451582]

26. Kameda-Smith MM, Iorio-Morin C, Winkler-Schwartz A, Ahmed US, Bergeron D, Bigder M, Canadian Neurosurgery Research Collaborative (CNRC). Smartphone Usage Patterns by Canadian Neurosurgery Residents: A National Cross-Sectional Survey. World Neurosurg 2018 Mar;111:e465-e470. [doi: 10.1016/j.wneu.2017.12.089] [Medline: 29277596]

27. BinDhim NF, Trevena L. Health-related smartphone apps: regulations, safety, privacy and quality. BMJ Innov 2015 Mar 05;1(2):43-45. [doi: 10.1136/bmjinnov-2014-000019]

28. Chanpimol S, Seamon B, Hernandez H, Harris-Love M, Blackman M. Using Xbox kinect motion capture technology to improve clinical rehabilitation outcomes for balance and cardiovascular health in an individual with chronic TBI. Arch Physiother 2017;7 [FREE Full text] [doi: 10.1186/s40945-017-0033-9] [Medline: 28824816]

29. Zahra F, Hussain A, Mohd H. Usability factors of mobile health application for chronic diseases. 2016 Presented at: The International Conference on Applied Science and Technology 2016; April 11-13, 2016; Kedah, Malaysia.

30. HSFR/HFG Project. HSFR/HFG End of Project Achievement Highlights - Amhara.: Health Finance and Governance Project, Abt Associates; 2018 Jun. URL: https://www.slideshare.net/HFGProject/ hsfrhfg-end-of-project-regional-report-amhara [accessed 2019-06-01]

31. Amhara National Regional State Bureau of Health. For Supply, Training and Installation of Solar photovoltaic Systems For Rural Health posts in North Gondar Zone. Ethiopian Herald. Bahir Dar: Ethiopian Press Agency; 2009 Jul 04. URL: http://www.ethiomarket.com/bid/2009/July09/bid_jul_4_amhara_national_regional_state_bureau_of_health.htm [accessed 2019-06-07]

32. Ma Q, Liu L. The Technology Acceptance Model: A Meta-Analysis of Empirical Findings. In: Advanced Topics in End User Computing, Volume 4. Hershey, PA: IGI Global; 2005:112-128.

33. Putzer GJ, Park Y. Are physicians likely to adopt emerging mobile technologies? Attitudes and innovation factors affecting smartphone use in the Southeastern United States. Perspect Health Inf Manag 2012;9:1b [FREE Full text] [Medline: 22737094]

34. Talwar YK, Karthikeyan S, Bindra N, Medhi B. Smartphone - A User-friendly Device to Deliver Affordable Healthcare A Practical Paradigm. J Health Med Inform 2016;7(3) [FREE Full text] [doi: 10.4172/2157-7420.1000232]

35. Nematollahi M, Faghiri K, Barati O, Bastani P. Smart Phone Acceptance among Physicians: Application of Structural Equation Modelling in the Largest Iranian University. J Biomed Phys Eng 2017 Mar;7(1):87-94 [FREE Full text] [Medline: 28451582]

36. Yasini M, Marchand G. Mobile Health Applications, in the Absence of an Authentic Regulation, Does the Usability Score Correlate with a Better Medical Reliability? Stud Health Technol Inform 2015;216:127-131. [Medline: 26262024]

37. Sandholzer M, Deutsch T, Frese T, Winter A. Predictors of students' self-reported adoption of a smartphone application for medical education in general practice. BMC Med Educ 2015 May 21;15:91 [FREE Full text] [doi: 10.1186/s12909-015-0377-3] [Medline: 25994310]

38. Grow JN, Vargo JD, Nazir N, Korentager R. Smartphone Applications in Plastic Surgery: A Cross-Sectional Survey of 577 Plastic Surgeons, Fellows, Residents, and Medical Students. Aesthet Surg J 2019 Nov 13;39(12):NP530-NP537. [doi: 10.1093/asj/sjz052] [Medline: 30810739]

39. Hsiao J, Chen R. Understanding Determinants of Health Care Professionals' Perspectives on Mobile Health Continuance and Performance. JMIR Med Inform 2019 Mar 18;7(1):e12350 [FREE Full text] [doi: 10.2196/12350] [Medline: 30882353]

40. Ganasegeran K, Renganathan P, Rashid A, Al-Dubai SAR. The m-Health revolution: Exploring perceived benefits of WhatsApp use in clinical practice. Int J Med Inform 2017 Jan;97:145-151. [doi: 10.1016/j.ijmedinf.2016.10.013] [Medline: 27919374]

41. Elavsky S, Smahel D, Machackova H. Who are mobile app users from healthy lifestyle websites? Analysis of patterns of app use and user characteristics. Transl Behav Med 2017 Dec;7(4):891-901 [FREE Full text] [doi: 10.1007/s13142-017-0525-x] [Medline: 28929368]

\section{Abbreviations}

AOR: adjusted odds ratio

IT: information technology

mHealth: mobile health 
Edited by L Buis; submitted 13.04.20; peer-reviewed by M Hassen, K Gashu, K Ganasegeran; comments to author 12.06.20; revised version received 26.10.20; accepted 22.01.21; published 26.03.21

Please cite as:

Teferi GH, Tilahun BC, Guadie HA, Amare AT

Smartphone Medical App Use and Associated Factors Among Physicians at Referral Hospitals in Amhara Region, North Ethiopia, in 2019: Cross-sectional Study

JMIR Mhealth Uhealth 2021;9(3):e19310

URL: https://mhealth.jmir.org/2021/3/e19310

doi: $\underline{10.2196 / 19310}$

PMID: $\underline{33769303}$

(C) Gizaw Hailiye Teferi, Binyam Cheklu Tilahun, Habtamu Alganeh Guadie, Ashenafi Tazebew Amare. Originally published in JMIR mHealth and uHealth (http://mhealth.jmir.org), 26.03.2021. This is an open-access article distributed under the terms of the Creative Commons Attribution License (https://creativecommons.org/licenses/by/4.0/), which permits unrestricted use, distribution, and reproduction in any medium, provided the original work, first published in JMIR mHealth and uHealth, is properly cited. The complete bibliographic information, a link to the original publication on http://mhealth.jmir.org/, as well as this copyright and license information must be included. 